\title{
Understanding relational conditions necessary for effective mentoring of black-owned small businesses: A South African perspective
}

\begin{tabular}{|c|c|}
\hline \multicolumn{2}{|c|}{$\begin{array}{l}\text { Authors: } \\
\text { Makatleho J. Matabooe }^{1} \\
\text { Elmarie Venter }^{1} \\
\text { Chantal Rootman }^{1}\end{array}$} \\
\hline \multicolumn{2}{|c|}{$\begin{array}{l}{ }^{1} \text { Department of Business } \\
\text { Management, Nelson } \\
\text { Mandela Metropolitan } \\
\text { University, South Africa }\end{array}$} \\
\hline \multicolumn{2}{|c|}{$\begin{array}{l}\text { Corresponding author: } \\
\text { Elmarie Venter, elmarie. } \\
\text { venter@nmmu.ac.za }\end{array}$} \\
\hline \multicolumn{2}{|c|}{$\begin{array}{l}\text { Dates: } \\
\text { Received: } 17 \text { May } 2015 \\
\text { Accepted: } 15 \text { Oct. } 2015 \\
\text { Published: } 29 \text { Mar. } 2016\end{array}$} \\
\hline \multicolumn{2}{|c|}{$\begin{array}{l}\text { How to cite this article: } \\
\text { Matabooe, M.J., Venter, E. \& } \\
\text { Rootman, C., 2016, } \\
\text { 'Understanding relational } \\
\text { conditions necessary for } \\
\text { effective mentoring of } \\
\text { black-owned small } \\
\text { businesses: A South African } \\
\text { perspective', Acta Commercii } \\
\text { 16(1), a327. http://dx.doi. } \\
\text { org/10.4102/ac.v16i1.327 }\end{array}$} \\
\hline \multicolumn{2}{|c|}{$\begin{array}{l}\text { Copyright: } \\
\text { (c) 2016. The Authors. } \\
\text { Licensee: AOSIS. This work is } \\
\text { licensed under the Creative } \\
\text { Commons Attribution } \\
\text { License. }\end{array}$} \\
\hline \multicolumn{2}{|c|}{ Read online: } \\
\hline 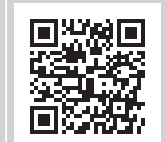 & $\begin{array}{l}\text { Scan this QR } \\
\text { code with your } \\
\text { smart phone or } \\
\text { mobile device } \\
\text { to read online. }\end{array}$ \\
\hline
\end{tabular}

Orientation: To gain an understanding of the relational conditions required for effective mentoring of black-owned small businesses.

Research purpose: To identify relational-based conditions for effective mentoring, which can be used to enhance business management skills of owner-managers of black-owned small businesses and eventually improve the survival of these businesses in South Africa.

Motivation for the study: By identifying relational-based conditions needed for effective mentoring of black-owned small businesses, recommendations can be put forward that could help achieve harmonious mentoring relationships and ultimately ensure effective mentoring of these businesses.

Research design, approach and method: An interpretivism paradigm was adopted and a qualitative research methodology was selected. Semistructured interviews were used to gauge the perceptions of participants about relational issues necessary for effective mentoring. Content and constant comparative analyses were used to analyse data.

Main findings: The findings revealed that conditions surrounding the knowledge and expertise of the mentor, experience and age of the mentor, approachability of the mentor, mutual respect, open communication, mutual trust and honesty, passion and patience of the mentor, mentee's willingness to learn, alignment of expectations, as well as culture sensitivity of the mentor are to be considered for effective mentor-mentee relationship.

Practical/managerial implications: Although mentoring is important to develop management skills of owner-managers, it is equally important that the mentor-mentee relationship is nurtured to achieve the desired outcomes of the relationship.

Contribution/value-add: The alarming failure rates of small businesses in general and blackowned small businesses in particular could be improved by providing effective mentoring programmes to owner-managers by ensuring harmonious mentor-mentee relationships.

\section{Introduction and background to this study}

There has been an increase of interest and research on the topic of mentoring, possibly because of the critical role that the concept plays in different disciplines (Gaunt et al. 2012:25). As such, there have been notable developments in the focus of mentoring research. For example, Haggard et al. (2011:283) state that previous research on mentoring focused on understanding the nature of mentoring and its key dimensions as well as mentee perspectives during mentoring sessions focusing mainly on career outcomes. However, studies such as those by Kram (1983; 1985) provided the foundation for more studies such that the focus of mentoring was then shifted from that of the mentee to include multiple topics (Haggard et al. 2011:283) such as, amongst others, the phases of mentoring (Kram 1983), network mentoring support (Lamb 1999), the influence of demographics on mentoring (Finkelstein et al. 2012; Ensher \& Murphy 2011), mediating variables between mentoring and mentee outcomes (Fleig-Palmer \& Schoorman 2011) and mentoring using technology (De Janasz \& Godshalk 2013). Despite the extensive research on mentoring, other aspects of mentoring, such as relational behaviours that result in effective mentoring relationships (Eller, Lev \& Feurer 2014:816; Janssen, Van Vuuren \& De Jong 2015:1; St-Jean 2012:1), have been scant (Janssen et al. 2015:1).

Previous research (e.g. Solansky 2010:676) indicates that because of the relationship that exists between the mentor and the mentee, it is important to investigate effective mentoring based on 
the interaction between these two individuals. St-Jean (2012:201) also suggests that effective mentoring is characterised by how well the mentor and mentee relate during mentoring processes. It is particularly important to identify relational conditions that may influence effective mentoring in South Africa as this country consists of diverse languages and ethnic groups (Warnich et al. 2011:191) which could have an impact on how mentors and mentees relate during mentoring processes.

Given the importance of mentoring in the development of skills, small business owner-managers in South Africa enrol for mentoring programmes to improve their management skills and ultimately their survival (Botha \& Esterhuyze 2012:12102; NEF Annual Report 2014). Nonetheless, these businesses still fail, which raises concerns about the effectiveness of mentoring programmes available for small businesses (NEF Annual Report 2014). The failure rate for small and medium-sized enterprises in South Africa ranges between $70 \%$ and $80 \%$ (ChiloaneTsoka \& Mmako 2014:379), which is a major challenge given the critical role these businesses play in the South African economy. Globally and in South Africa, small and medium-sized enterprises dominate the economy, and their contribution to most countries' gross domestic product and employment creation cannot be ignored (Fatoki 2011:193). Hence, the survival of small businesses and in particular that of black-owned small businesses is a major concern to the South African government (Rogerson 2013:141). A small business in this study refers to a black-owned business that is independently owned and which employs fewer than 50 people.

The reason why this study focuses on black-owned small businesses is because black owner-managers are often not sufficiently educated to be entrepreneurs (Ndedi 2013:197). Even though the black community is the largest in South Africa, representing $79.4 \%$ of the population (Lucassen et al. 2013), this population group has a low participation rate in entrepreneurial activities compared to other ethnic groups (Nkosi, Bounds \& Goldman 2013:2; Preisendörfer \& Bitz 2012:2). This is possibly because of the fact that entrepreneurship is a new territory for the black community who may have perceived starting businesses as a way out of poverty (Preisendörfer \& Bitz 2012:2). Therefore, developing the black community, which is the dominant ethnic group and the poorest in the country (Ndedi 2013), to become key contributors of the South African economy is essential in addressing unemployment and inequality issues in this country (Small Business Connect 2014).

Against this background, it is important to investigate the relational conditions required for effective mentoring of black-owned small businesses in South Africa. Knowledge on the relational conditions necessary for mentoring relationships is fundamental for creating proper mentoring structures for small businesses as these could guide mentors to maximise the outcomes of mentoring (St-Jean 2012:201).

\section{Purpose and primary objective}

The purpose of this study is to identify the most important relational conditions necessary for effective mentoring in black-owned small businesses, which can be used to enhance the business management skills and decision-making of these owner-managers and eventually improve the survival of these businesses in South Africa. Although the literature provides ample research on small businesses in general, research on mentoring of these businesses, and consequently black-owned businesses, is limited (Clutterbuck \& Abbott 2012:74; McKevitt \& Marshall 2015:264).

\section{Literature Defining mentoring}

As mentioned earlier, there has been an increase of interest and research on the topic of mentoring. Watson (2004:67) observes that as a result of this increased interest, mentoring has developed differently from scientific and functional disciplines. As such, defining mentoring has been a challenge that researchers are faced with, which could be attributed to the different meanings attached to this concept (Ghosh 2012:154). Kram (1985), in Haggard et al. (2011:286), also acknowledges that mentoring could mean different things to different people depending on the context and objectives attached to the concept. Therefore, to make provision for these diverse perceptions, varied definitions of what mentoring entails have been established by researchers (Haggard et al. 2011:286). Nonetheless, in this study, mentoring is defined based on the mentoring definition given by Swanepoel, Strydom and Nieuwenhuizen (2010:65), as well as Cline (2011:36), and refers to a relationship between a mentor and mentee in which learning and experimentation can occur, potential skills can be developed, and in which results can be measured in terms of competencies gained.

Despite the popularity of mentoring, there seems to be confusion about the distinction between mentoring and coaching as these are both developmental relationships (Fletcher \& Mullen 2012:250). Even though Herholdt (2012:28) acknowledges that a practical differentiation between mentoring and coaching is a vague and difficult one, McKevitt and Marshall (2015:264) explain that coaching and mentoring are distinct relationships in the context of entrepreneurship. For example, coaching has a short-term focus with emphasis on immediate micro-related issues (Fajana \& Gbajumo-Sheriff 2011:423), whilst mentoring has a longer term focus with emphasis on micro- and macrorelated issues (Cline 2011:36). As such, a mentor may choose to use coaching techniques within the mentoring relationship (Fajana \& Gbajumo-Sheriff 2011:424).

Because mentoring is defined as a relationship, it is also important to define the two stakeholders relevant in mentoring relationships, namely the mentor and the mentee. A mentor is defined as a person with expertise in a variety of areas of interest and who is willing to share wisdom with 
others (Goosen \& Van Vuuren 2005:62). A mentee or protégé is a person who is committed to expanding his or her capabilities by learning from others (Ayinde 2011:2). In order for these two stakeholders to have an effective mentoring relationship, it is important to nurture and embrace the relationship they have (Herholdt 2012:36).

\section{Nature of mentoring relationships}

Solansky (2010:676) explains that the mentoring relationship is described as a complex relationship that is based on social exchange between at least two individuals. The reason why this relationship is regarded as complex is because the relationship facilitates the development of one of the parties (Freedman 2009:173), namely the mentee. Yet it is expected that not only the mentee gains from the relationship, but that the mentors and businesses providing mentoring also receive related benefits (Ensher \& Murphy 2011:254). Again, the relationship is complex in that it is the responsibility of both the mentor and mentee to work in harmony to achieve the objectives for which the relationship exists (Terblanché 2011:57). Hence, it is advised that both the mentor and mentee should each do their part for the relationship to be successful (Hattingh, Coetzee \& Schreuder 2005:41).

Previous research on mentoring (e.g. Ayinde 2011:5; Freedman 2009) has identified organisational and relational conditions necessary for effective mentoring. However, as this study focuses on relational conditions, it is deemed necessary to define relational conditions. These are referred to as the conditions that are necessary to enhance the personal interaction between mentors and owner-managers during the mentoring process. It should be noted that in literature some researchers (e.g. Kathleen 2014) refer to relational conditions, as is the case in this study, whilst others (see Janssen et al. 2015) refer to relational factors that are necessary for the effectiveness of mentoring relationships.

The literature across multiple disciplines has revealed numerous conditions commonly found in effective mentoring relationships (Distelberg \& Schwarz 2015:193). For example, in a survey determining the key components of an effective mentoring relationship (Eller et al. 2014:818), the participants indicated that honesty, mutual trust, respect, constructive feedback and open communication are necessary in achieving successful mentoring relationships. The study of Ayinde (2011:5) confirms that good communication, being able to listen to one another, trust and respect strengthen the relationship between the mentor and mentee. Distelberg and Schwarz (2015:197), as well as Herholdt (2012:94), assert that the mentoring relationship should engender commitment from both the mentor and mentee to reach the desired outcomes of the mentoring relationship. The ability to treat with the utmost confidentiality everything discussed in a mentoring relationship is also essential. According to Conn (2013), mentees need to feel confident that they can reveal problems in a confidential relationship. In the same manner, mentors should show loyalty towards the relationship and maintain confidentiality of the information shared during the mentoring process (Leck \& Orser 2013). In examining cultural influences in mentoring endeavours, Kochan et al. (2015:87) argue that the effectiveness of mentoring relationships depends on cultural issues inherent within individuals in a mentoring relationship. The influence of culture on mentoring relationships is especially important when people from different cultures work together (Allen et al. 2008:347). This is relevant to the South African context as the black community in this country consists of nine different traditional cultural groups (Adams, Van de Vijver \& De Bruin 2012:379).

As can be deduced from the literature review, numerous relational conditions are necessary to ensure the effectiveness of any mentoring relationship. Once these conditions are taken into consideration in a mentoring relationship, such a relationship is bound to make a significant impact on the career of the mentee and growth of the business in which the mentee operates (Herholdt 2012:59). Therefore, in an attempt to enhance effective mentoring relationships during mentoring of black-owned small businesses, the following research questions are presented:

- What are the perceptions of mentors, mentees and board member/managers of the relational conditions necessary to ensure effective mentoring relationships?

- What guidelines and recommendations can be put forward to help mentors and mentees of black-owned small businesses to achieve harmonious mentoring relationships?

\section{Research paradigm and methodologies}

An interpretivism paradigm was adopted in this study. The central idea behind an interpretivism paradigm is to uncover meanings in a phenomenon as it is understood by an individual or a group of individuals and to describe these meanings in an understandable manner to those who experience the phenomenon (Remenyi 2007:218). A qualitative methodology was adopted as the interpretivism paradigm is often associated with qualitative research methodologies.

Zikmund et al. (2013:139) suggest that there are several methods to choose from when following a qualitative research methodology. In view of the purpose and objective of this study, the phenomenological method of research is appropriate for this study. Phenomenology is a study of how things are perceived based on individual experiences and the meanings that these things have in these experiences (Zikmund et al. 2013:136).

Despite the popularity of mentoring and the increased use of mentoring as a developmental tool, little information exists on mentoring for small businesses in South Africa (Clutterbuck \& Abbott 2012:74). As the primary objective of this study is to gain an understanding of the relational conditions required for effective mentoring of black-owned 
small businesses, exploratory research was considered most appropriate to understand the lived experiences of the participants and the meanings they make about such experiences (Young \& Atkinson 2012:51). These experiences should help identify the relational conditions necessary for effective mentoring so that recommendations can be put forward that could help achieve harmonious mentoring relationships and ultimately effective mentoring of blackowned small businesses.

\section{Population and sampling}

The population for this study is identified as South African institutions that provide mentoring to black-owned small businesses. The study took place in two provinces of South Africa, namely the Eastern Cape and Gauteng. The selection of these two provinces was based on the varying magnitudes of the two provinces in terms of wealth, as well as the size and distribution of small businesses within these provinces. For instance, Gauteng is the richest province (Jakkie 2014:6) and is the leading province in terms of the number of small businesses operating in both the formal and informal sectors (DTI Report 2008:67). In contrast, the Eastern Cape is the poorest province in South Africa ( $\mathrm{O}^{\prime}$ Donoghue \& Shackleton 2013:444) with a large rural population and it accommodates higher proportions of informal businesses (DTI Report 2008:67). Two mentoring institutions were selected from each province, which amount to a total of four institutions.

Because small businesses exist in almost every business industry (Moyes, Whittam \& Ferri 2012:142), quota sampling was adopted to enable participant representation from various industries. Within each of the four mentoring institutions selected, mentors, mentees and board member and/or managers were identified. A total of 21 participants, namely 6 mentors, 12 mentees and 3 board members/ managers from the mentoring institutions participated in this study.

\section{Data collection}

To gain a deeper understanding of the relational conditions required for effective mentoring of black-owned small businesses, semistructured interviews were used to collect data from the participants. Myers (2013:125) explains that when semistructured interviews are used, there is more flexibility as other topics could emerge during the conversation, whilst at the same time the preformulated questions provide focus and a measure of consistency. Interview questions included, but were not limited to, the following:

- In your opinion, what roles should a mentor play when mentoring?

- In your opinion, are there any challenges to successful mentoring of small businesses?

- Generally, what do you perceive as the contributing conditions of a successful or failed mentoring relationship?

The aim of these interview questions was to understand mentoring relationships as experienced and perceived by the participants. All interviews were conducted in English and were captured on an audio tape recorder to be transcribed verbatim.

\section{Data analysis}

Considering that little is known about the mentoring conditions of small businesses (Clutterbuck \& Abbott 2012:74) and therefore of black-owned small businesses, a combination of deductive and inductive coding methods was adopted in this study. Whilst this study is based on gaining greater insight into relational conditions required for effective mentoring of black-owned small businesses and is focused on reading data to develop themes and sub-themes (inductive codes), it has also considered themes and sub-themes from the literature (deductive codes). This means that inductive codes were used as a starting point to identify themes and sub-themes in the data. Thereafter, the themes and subthemes that were similar to the literature were merged and adopted in this study.

The coding framework was developed following Tesch's eight-step model as described in a study by De Vos et al. (2002:340-341). By using the Tesch's eight-step model in this study, the transcripts were first read for each group of participants. This enabled the researcher to identify words and phrases that were common to each group. Whilst trying to understand the information contained in the transcripts, thoughts and ideas were written down as they came to mind. Similar topics that emerged from these transcripts were categorised together, formed and placed next to the relevant words or phrases in the transcripts. These words and phrases were analysed further to discover any underlying themes and sub-themes to simplify the coding process. Following this, themes and sub-themes were grouped into relevant categories, enabling a preliminary analysis to be performed. This process allowed for comparison of differences in the perceptions and experiences across the three groups of participants.

Once the Tesch's eight-step model was completed, a combination of content analysis and constant comparative analysis was identified as the most suitable techniques for data analysis in this study. Content analysis was used to find the meaning of the transcribed interviews (Stam 2008:26), whilst constant comparative analysis was used to identify similarities and differences amongst the three groups of participants (Shi 2008:158). The variations across the three groups of participants provided an understanding into relational conditions that are necessary to ensure effective mentoring of black-owned small businesses in South Africa.

\section{Trustworthiness}

According to Eriksson and Kovalainen (2008:290), one of the challenges confronting qualitative researchers is ensuring trustworthiness. Trustworthiness is a concept that addresses the issues of validity and reliability of qualitative research (Elo et al. 2014:2). Similarly, in this study, trustworthiness 
issues were addressed through considering validity and reliability as described in the subsequent sections.

\section{Validity}

The researchers received participants' feedback on the data collected to confirm that the information recorded was accurate and correct. In addition, empirical findings of this study were compared with previous research on mentoring in other contexts to ensure the validity of this study.

\section{Reliability}

Reliability was ensured by firstly constructing a thorough and well-documented methodology section. Secondly, reliability was ensured by proper documentation of all the important information pertaining to this study, which included the interview schedule, interview transcripts and other secondary data for future reference.

\section{Ethical considerations}

The researchers have obtained ethics approval from the academic institution at which this study was conducted. Participants were given the opportunity to decline or withdraw from participation in the study. Even though no confidential information such as financial records was required, participants were ensured that their responses would be treated with the strictest confidentiality.

\section{Findings}

The primary objective of this study was achieved by gaining an understanding of the relational conditions required for effective mentoring of black-owned small businesses. Table 1 provides a summary of the themes and quotes that illustrate the relational conditions required for effective mentoring of black-owned small businesses.

\section{Knowledge and expertise}

The mentor possessing knowledge and expertise in a mentoring relationship was reported as an important relational condition for effective mentoring. One mentor highlighted the importance of being skilled to mentor small businesses. This mentor stated: 'I don't think I was a good mentor ... I could have improved my skills in the mentoring ...' Mentees also indicated that mentors should be knowledgeable and have expertise in their respective industries. For example, mentees explained that a mentor should be someone with 'expertise based on our industry ... expertise in terms of dealing with small businesses ...' and that 'even if he is not or she is not educated, highly qualified, but someone with knowledge'. Similarly, the board member/managers pointed out that the level of knowledge is important for the mentoring of blackowned small businesses. These board member/managers noted that what is important about the competencies of mentors is 'their level of knowledge on the subject matter' and that 'it must be someone who has got formal training in the specific field'.

\section{Experience and age}

Experience in a mentoring relationship was valued by the participants across the three groups of participants. A novice mentor reported that it was my first time and also it's a challenge when you doing the mentoring session and you come up with the questions that you are unable to answer ...' In addition, responses from mentors indicated that 'you can't have the experience generally ... they [mentors] had to be older' and that the mentor should have 'more experience in business than the mentee ...' The younger mentors indicated that age should not be an issue for mentoring relationships, whilst only some older mentors linked the experience of mentors to age.

In contrast, mentees related the level of experience to the age of the mentor. Mentees stated that mentors 'need to have owned a business' and that 'the one who is older has got a lot of experience'. One mentee explained that 'when you get younger people mentoring you, there is limited advice'. Another mentee also emphasised experience by stating that 'experience goes hand-in-hand with qualifications'. Nonetheless, other mentees were of the opinion that the age of the mentor should not be an issue. One mentee explained that 'If somebody is younger than me but when he's giving me the mentorship or he's mentoring and you see the necessary skills in him ... I don't see any problem at all'. Another mentee explained that 'If the mentor is trained ... it doesn't matter how old he is'.

Despite the contradictory findings, the board member and/ or managers emphasised that a mentor 'should be able to speak from experience ... be able to relate to situations', and that 'unfortunately the norm is that the older people obviously would have had more experience'. Another board member and/or manager explained that 'the same age might point to similar experiences and the same level of knowledge or expertise'.

\section{Approachability of the mentor}

The aspect of approachability of the mentor was mentioned by one mentor and a large number of mentees as influencing the mentoring relationship. The mentor mentioned that 'the mentor's approach towards the mentee' is important in a mentoring relationship. This mentor further explained that as a mentor, 'you don't want to dominate them [mentees]; you want to find out how can I help you to make your business a success'. Similarly, mentees indicated that having an approachable mentor is important in a mentoring relationship. For example, a mentee emphasised that a mentor 'must be someone who is approachable ... someone whom you are not scared [of]; like you can ask anything'.

\section{Mutual respect}

The participants expressed their views on the important role that both a respectful mentor and mentee play in the mentoring relationship. With regard to a respectful mentor, 
TABLE 1: Themes and quotes that illustrate the relational conditions required for effective mentoring of black-owned small businesses

\begin{tabular}{|c|c|c|c|}
\hline Themes & Mentors' quotes & Mentees' quotes & Board member and/or managers' quotes \\
\hline $\begin{array}{l}\text { Knowledge and } \\
\text { expertise }\end{array}$ & $\begin{array}{l}\text { 'I don't think I was a good mentor ... I could have } \\
\text { improved my skills in the mentoring ...' }\end{array}$ & $\begin{array}{l}\text { 'expertise based on our industry ... expertise in terms } \\
\text { of dealing with small businesses ...' } \\
\text { 'even if he is not or she is not educated, highly } \\
\text { qualified, but someone with knowledge' }\end{array}$ & $\begin{array}{l}\text { 'their level of knowledge on the subject matter' } \\
\text { 'it must be someone who has got formal training } \\
\text { in the specific field' }\end{array}$ \\
\hline $\begin{array}{l}\text { Experience and } \\
\text { age }\end{array}$ & $\begin{array}{l}\text { 'it was my first time and also it's a challenge when } \\
\text { you doing the mentoring session and you come } \\
\text { up with the questions that you are unable to } \\
\text { answer ...' } \\
\text { 'you can't have the experience generally ... } \\
\text { they [mentors] had to be older' }\end{array}$ & $\begin{array}{l}\text { 'the one who is older has got a lot of experience' } \\
\text { 'when you get younger people mentoring you, } \\
\text { there is limited advice' } \\
\text { 'If the mentor is trained ... it doesn't matter how } \\
\text { old he is' }\end{array}$ & $\begin{array}{l}\text { 'should be able to speak from experience ... } \\
\text { be able to relate to situations' } \\
\text { 'unfortunately the norm is that the older people } \\
\text { obviously would have had more experience' } \\
\text { 'the same age might point to similar experiences' }\end{array}$ \\
\hline $\begin{array}{l}\text { Approachability } \\
\text { of the mentor }\end{array}$ & $\begin{array}{l}\text { 'the mentor's approach towards the mentee' } \\
\text { 'you don't want to dominate them [mentees]; } \\
\text { you want to find out how can I help you to make } \\
\text { your business a success' }\end{array}$ & $\begin{array}{l}\text { mentor 'must be someone who is approachable ... } \\
\text { someone whom you are not scared [of]; like you can } \\
\text { ask anything' } \\
\text { 'well ... I think it's attitude ...' }\end{array}$ & \\
\hline Mutual respect & $\begin{array}{l}\text { 'respect the mentors, they [mentors] will be able } \\
\text { to give [show] that respect' } \\
\text { 'Respectful not to [in] the sense that you [mentee] } \\
\text { don't want to talk because a lot of people say, } \\
\text { "I respect you too much to ask you questions"' }\end{array}$ & $\begin{array}{l}\text { 'treating mentees as adults' } \\
\text { 'saying the right things, using the right words' } \\
\text { 'If I respect you [mentor] ... it makes you free to want to } \\
\text { do more for me...' } \\
\text { 'if you respect your mentor, they can respect you' }\end{array}$ & $\begin{array}{l}\text { 'have the admiration and the respect' } \\
\text { [of mentees] } \\
\text { 'be a respectable person ...' }\end{array}$ \\
\hline $\begin{array}{l}\text { Trust and } \\
\text { honesty }\end{array}$ & $\begin{array}{l}\text { 'there has to be a good trusting relationship' } \\
\text { 'tell them [mentees] the honest [truth]' }\end{array}$ & $\begin{array}{l}\text { '[ mentoring is] about trust ... if he believes in me ... } \\
\text { I can believe in his abilities' } \\
\text { 'should be somebody ... you can trust ... if you share } \\
\text { something confidential ... it's going to be very safe' }\end{array}$ & $\begin{array}{l}\text { 'the relationship will never work without trust ... } \\
\text { if I do not trust that what I tell you will be kept } \\
\text { confidential, then trust isn't there' }\end{array}$ \\
\hline $\begin{array}{l}\text { Passion and } \\
\text { patience of the } \\
\text { mentor }\end{array}$ & & $\begin{array}{l}\text { 'passion to work with small businesses' } \\
\text { 'be very patient' } \\
\text { 'want to see the growth of the mentee ...' } \\
\text { 'the voice that keeps you going' } \\
\text { 'the encourager' } \\
\text { [mentor] 'shouldn't be your therapist ... to talk about } \\
\text { your personal life' }\end{array}$ & $\begin{array}{l}\text { 'have the patience and understanding of the } \\
\text { type of people that they are being asked to } \\
\text { deal with ... be selfless' } \\
\text { 'passion for people development' } \\
\text { [mentors] 'need to understand the role of } \\
\text { psychology' } \\
\text { [mentors] 'end up assisting in business-related } \\
\text { issues, but end up being a counsellor as well' }\end{array}$ \\
\hline $\begin{array}{l}\text { Alignment of } \\
\text { expectations }\end{array}$ & $\begin{array}{l}\text { 'have huge expectations ... sometimes unrealistic' } \\
\text { 'there's too many stories ... that people are } \\
\text { getting rich ... the expectation is that they want } \\
\text { their turn as well ...' }\end{array}$ & $\begin{array}{l}\text { 'they promised us that they are going to do marketing' } \\
\text { 'the most important thing that I was looking for is } \\
\text { funding' } \\
\text { 'I think they [expectations] have been met' }\end{array}$ & $\begin{array}{l}\text { 'they think this is part of service delivery ... } \\
\text { they are not expected to pay a cent' }\end{array}$ \\
\hline Cultural issues & $\begin{array}{l}\text { 'take them [cultural differences] aside of the } \\
\text { working ethics' } \\
\text { 'be culturally sensitive' } \\
\text { we're different people and just be sensitive in [to] } \\
\text { different culture beliefs ...' }\end{array}$ & 'it's good to learn from one another, of our cultures' & $\begin{array}{l}\text { [mentors] 'need to understand it [cultural } \\
\text { difference]' } \\
\text { 'understanding of group dynamics is also } \\
\text { important ... be accommodating where need be' }\end{array}$ \\
\hline
\end{tabular}

mentees stated that respectful mentors treat mentees as 'adults' and that 'saying the right things, using the right words' also demonstrates that mentors are respectful. The importance of a respectful mentor was also noted by board member/managers who explained that mentors should 'have the admiration and the respect' of mentees, and that a mentor should be 'a respectable person ...'

Both mentors and mentees expressed their views on mentees displaying respect during mentoring interactions. For example, a mentor noted that if mentees 'respect the mentors, they [mentors] will be able to give [show] that respect'. However, another mentor cautioned that being respectful does not mean that questions should not be asked by mentees during the mentoring process, as evidenced in this quotation: 'Respectful not to $[\mathrm{in}]$ the sense that you don't want to talk because a lot of people say, "I respect you too much to ask you questions"'. This means that being respectful should not stop mentees from being free to express their views and ask questions during the mentoring process.

Mentees also expressed their views on the significance of themselves showing respect towards mentors in a mentoring relationship. These mentees expressed their views saying: 'If I respect you [mentor] ... it makes you free to want to do more for me ...' and that 'if you respect your mentor, they can respect you'. One mentee further explained that being respectful towards a mentor is demonstrated by 'saying the right things; using the right words ...'

\section{Communication}

All three groups of participants were of the opinion that effective communication can be achieved through open 
communication between the mentor and mentee. The mentors stated that when open communication exists in a mentoring relationship, mentees become 'comfortable to speak ...' during mentoring processes, and that a mentor 'must be a good communicator' to enable open communication. Mentees noted that a mentor should 'be free or open', 'be able to listen ... in order to give an answer' and 'must allow for anything to be able to be said in the mentorship'. Another mentee explained that in the absence of communication, 'there will be a misunderstanding' in the relationship. The board member and/or managers also felt that the ability to communicate is crucial in a mentoring relationship. They expressed their views, saying that 'any person, to be a mentor, must have the ability to communicate...' and '... be able to ask the right questions ... be great listeners ... also listening for what is not said ...'.

Relating to communication, the language being used during mentoring sessions is regarded as an important relational condition. Mentors mentioned that some people 'don't even understand English ...' and that 'not all people are educated'. Another mentor expressed these views saying: 'I was doing mentoring to more illiterate-level people who wouldn't want me to speak with them in English ... that emanates from their background schooling'. Mentees also acknowledged that using English during mentoring sessions is a challenge because they prefer using 'the vernac ... our home languages' during mentoring interactions and that 'other people are not comfortable with the English'.

Another aspect related to communication is intercultural communication. A mentor expressed his views saying that 'there's a lot of cultural differences between the different societies ...' This mentor explained that it is important that 'the message that is conveyed is understood by the recipient of the message'. Another mentor explained that the challenge exists when 'it's black to black ... a culture of people ... listening to the older people'. A mentee also expressed his views saying: 'If you are not aware how my culture should be practised, how will you know ... when you talk to me as an elder to you ... you are supposed to stand or sit down or call me "Mr"...'

\section{Trust and honesty}

The participants highlighted the importance of trust and honesty between the mentor and mentee. Mentors in the current study emphasised that 'there has to be a good trusting relationship' and that during the interactions, mentors should be bold to 'tell them [mentees] the honest [truth]'.

An example of the statements made by mentees on trust and honesty in the mentoring relationship is that '[mentoring is] about trust ... if he believes in me ... I can believe in his abilities'. It was also evident from mentees' perceptions that confidentiality of information during the mentoring process is strongly linked to trust and honesty. For example, mentees stated that 'a mentor should be somebody ... you can trust ... if you share something confidential ... it's going to be very safe' and that 'if you want to share something very confidential, you must obviously trust that person'. Nonetheless, mentees explained that the mentoring relationship should be professional at all times and that 'things that are personal ...' and 'what happens between me and my fiancé' should not be shared with the mentor.

The board member and/or managers also linked the importance of trust with confidentiality of information in mentoring relationships. According to these participants, 'the relationship will never work without trust ... if I do not trust that what I tell you will be kept confidential, then trust isn't there' and that a mentor 'can't just divulge information about the mentee or a client to any other person'.

\section{Passion and patience of the mentor}

The mentees and board members considered the passion and patience of the mentor as an important relational condition that should be in place in a mentoring relationship. Mentees noted that mentors should possess 'passion to work with small businesses', 'be very patient' and that they should 'want to see the growth of the mentee ...' It should be noted that although mentees indicated that it is important to have a patient mentor, one mentee noted that it is equally important for a mentor to have boundaries to the extent of tolerance of mentees because 'a mentor can't always be saying, "Yes, yes, yes"'. The board member/managers also emphasised that a mentor should 'have the patience and understanding of the type of people that they are being asked to deal with ... be selfless' and have 'passion for people development' to achieve harmonious mentoring relationships with mentees.

Linking to passion and patience of the mentor, emotional support by the mentor was considered important for a mentoring relationship. A mentee explained that mentors are 'the voice that keeps you going'. Mentees further explained that the mentor should be 'the encourager', 'must also fit [in] our shoes' and 'know how to sympathise'. Again, mentees alleged that 'if he [mentor] can't help you, he can refer you to somewhere'. Whilst most mentees acknowledged the importance of having a mentor who provides emotional support and encouragement, contradictory views were observed on what constitutes emotional support provided by mentors. Some mentees emphasised that the role of a supportive mentor should not be exploited, saying that mentors 'shouldn't be your therapist ... to talk about your personal life' and that 'I have people who I can express that kind of stuff [emotions] with in a satisfactory interaction'. Board member/managers also acknowledged the importance of emotional support in a mentoring relationship. They explained that mentors 'need to understand the role of psychology' and that mentors 'end up assisting in businessrelated issues, but end up being a counsellor as well'.

\section{Mentee's willingness to learn}

The participants noted that mentees should be dedicated and willing to learn during the mentoring process. Mentors pointed 
out that a mentee's willingness to learn is demonstrated by being a 'self-starter ... initiate things [mentoring activities] ... follow through on matters ...' and also through 'dedication ... a desire to be able to succeed'. Mentees also realised the importance of showing willingness towards their own learning, saying: 'we have to commit ourselves to this programmes', 'do whatever [what] a mentor tells us to do' and 'we need to dedicate ourselves'. One mentee noted that mentees often engage in and fail to commit to mentoring because of the wrong reasons, saying that the biggest mistake when people walk into institutions ... they expect [name withheld] to do everything ...' The board member/managers collectively explained that 'mentees should be eager to soak up as much information as possible from the mentor', 'they must be inspired to get somewhere with their business' and that 'they must be diehards. They must be slave-drivers to themselves'. These quotes demonstrate board member/managers' views that mentees should be willing to learn during the mentoring process.

In this study, mentees' receptiveness to feedback is another aspect that demonstrates mentees' willingness to learn. The mentors stated that mentees should be able to deal with feedback, 'whether it be negative or positive' and that mentees 'need to be open to, not necessarily criticism, but to advice ...' Only one mentee noted the importance of being receptive to feedback from mentors. This mentee stressed that mentees should 'take everything as it comes ... whatever feedback, positive or negative'. Similarly, the board member/ managers stressed that 'mentees should be receptive ... to whatever advice they are given ...' and that mentees 'need to be able to listen to suggestions and listen to questions properly...'

\section{Alignment of expectations}

The importance of the alignment of expectations in a mentoring relationship was observed across the three groups of participants. In particular, mentors raised their concerns that mentees 'have huge expectations ... sometimes unrealistic' and that 'there's too many stories ... that people are getting rich ... the expectation is that they want their turn as well ... it's almost like a hand-out mentality ... if they'd come onto the programme ... properly briefed ... they should not have that expectation'.

The issue of unrealistic mentee expectations was also highlighted by one board member and/or manager, who described the unrealistic expectations of owner-managers as 'a culture of expectancy to say government must give ...' Another board member/manager explained that mentees expect that the 'institution is funded by government ... so they think this is part of service delivery ... they are not expected to pay a cent'.

On the other hand, most of the mentees expressed disappointment with their mentoring institutions because their mentoring expectations had not been met. Varied expectations were noted by these mentees. Examples of mentees' expectations are evident in these quotations: 'for them to give us some training or to take us to some trainings', 'someone will be able to give me an opportunity ... associate me with like good people according to my business', 'they promised us that they are going to do marketing' as well as 'the most important thing that I was looking for is funding'.

Despite the fact that most mentees noted that their expectations about mentoring had not been fulfilled, two mentees expressed their satisfaction with the mentoring programme and said: 'I think they [expectations] have been met' and 'I think the mentorship has been tremendous ... I think majority of the sessions I had ... have been quite productive, informative and educational'.

\section{Cultural issues}

The three groups of participants stated that it is important to acknowledge that cultural differences could exist between mentors and mentees, which can influence mentoring relationships. However, these participants indicated that these cultural differences should not become a challenge to the smooth running of mentoring programmes. One mentor indicated that mentors should 'take them [cultural differences] aside of the working ethics'. Although mentors indicated that cultural differences should not influence mentoring relationships, some mentors explained that mentors should 'be culturally sensitive' and that 'people need to understand ... we're different people and just be sensitive in [to] different culture beliefs ...'

Similarly, most mentees noted that cultural differences between mentors and mentees should not have any impact on their relationship, saying 'If we have to take culture into consideration, we are going to have a problem' and 'your cultures might clash in regards to what I think is wrong and what you think is right'. Instead, these mentees said: 'at some point, I believe it's good to learn from one another, of our cultures' and 'I will learn to understand the things he likes'. In contrast, one mentee alleged that the diverse values, beliefs and religions in a mentoring relationship did have an impact on the mentoring programme she participated in. The mentee stated that 'it's good if you are a Christian to be mentored by a Christian ...'

The board member/managers acknowledged the diverse cultures that exist within South African communities. Like the mentors, they emphasised that cultural differences between the mentor and mentee should not influence the effectiveness of mentoring relationships. They felt that mentors 'need to understand it [cultural difference]' and that the 'understanding of group dynamics is also important ... be accommodating where need be'. Despite the fact that the board member/managers alleged that cultural differences should not influence the effectiveness of mentoring relationships, one board member/manager reported that mentors have indicated that cultural differences 'impacted on their relationship in terms of being straightforward, being assertive and being able to communicate your needs 
appropriately and not to be apologetic about it'. This board member/manager further explained that they 'have had a request that they [mentees] want to deal with a mentor who is Christian'.

\section{Discussion and recommendations}

The findings of this study reveal that the majority of the participants acknowledge the importance of good relations between mentors and mentees during mentoring processes. From the participants' responses, 10 key relational conditions were identified as important during mentoring of black owner-managers in South Africa.

The extent to which mentors are knowledgeable and able to transfer this knowledge to mentees, as well as possessing expertise necessary to develop owner-managers, was found to have an impact on the effectiveness of mentoring relationships. De Janasz and Godshalk (2013:760) concur that when mentees perceive that their mentors have enough knowledge that will guide their career towards success, mentees relate well with their mentors.

Having an experienced and older mentor was suggested as important as it strengthens the relationship between the mentor and mentee. To become experienced mentors of small businesses, the mentors themselves must have owned a business because business decisions should not be based on reading books, but rather on experience. Previous research presents different views on the significance of experience of the mentor in the effectiveness of mentoring relationships. For example, McGill (2011:105) posits that mentors should be able to share their own challenging experiences with the mentees in order to facilitate learning. By contrast, Mann and Tang (2012:489) did not support the notion that the experience of the mentor is important in the mentoring relationship. The study in question found that it was preferable to have a less experienced mentor because the mentor's experience would be more recent, eliminating the generation gap where old concepts are presented in current situations. In addition, the findings of this study link the level of experience of mentors to their age. The idea of experience being linked to age is inherent in the traditional theory of mentoring whereby a mentor is referred to as someone who is older than the mentee and is experienced in the field to impart knowledge to the younger individual. Therefore, there could still be challenges to mentoring relationships that do not follow the traditional older-mentor and younger-mentee combination (Finkelstein et al. 2012:809).

The findings of this study suggest that approachability of the mentor is important in ensuring the effectiveness of mentoring relationships. Being approachable is described as having a positive attitude towards mentees, as well as creating an environment that allows mentees to address issues freely, and not making mentees feel dominated in the relationship. This correlates with the research findings of Little, Kearney and Britner (2010:196) who found the importance of their mentors' approachability as one aspect that influences the quality of the mentoring relationship.
The participants of this study also expressed their views on the important role that mutual respect plays in the mentoring relationship. It is important that both mentors and mentees know how to speak to one another. In particular to mentors, they should use the right words to give advice, and treat mentees as adults. Eller et al. (2014:818) states that when mentors respect their mentees, that respect encourages mentees to work harder because they would not want to disappoint their mentors. At the same time, mentees must show that they respect their mentors' opinions, ideas and decisions made during the relationship (Cunningham \& Hillier 2013:46).

The findings of this study revealed that creating a comfortable and open environment to enable mentees to express their views freely has an impact on effective mentoring relationships. When open communication exists in a mentoring relationship, mentors listen to the views of the mentees, including taking note of both verbal and nonverbal communication and knowing how to respond accordingly. McGill (2011:105) is in support of these findings, stating that open communication between both parties enhances a learning environment that unveils even the cultural norms and expectations of which mentees would be otherwise unaware.

A relationship characterised by trust and honesty is essential in a mentoring relationship. It is also evident in the current study that trust and honesty are strongly linked to confidentiality of information in a mentoring relationship. Thus, mentors and mentees need to be honest with each other about the information that is being shared, believe in the abilities of one another and should not share information with third parties. Eller et al. (2014:818) also suggests that it is important to trust and appreciate each other in a mentoring relationship. According to these authors, mentees relate well with their mentors when they believe and trust in the ability of mentees.

A mentor who demonstrates the qualities of passion and patience is described as having high levels of commitment and this could have a positive impact on the effectiveness of mentoring relationships. According to the participants, a passionate and patient mentor is someone who is selfless and enjoys empowering mentees, who is tolerant towards these mentees and believes that their businesses can be successful. Similarly, in a study conducted by Eller et al. (2014:817) mentees reported that they need mentors who have a passion for mentoring for effective mentoring relationships.

The extent to which mentees demonstrate their willingness to learn is described as an indication of their commitment to the mentoring relationship. A willingness to learn refers to mentees being dedicated and inspired to succeed in business, being able to execute mentoring activities, doing what is required of them and being hardworking during the mentoring process. This is in accordance with Leck and Orser (2013:416) who state that mentees need to demonstrate a genuine willingness to learn from their mentors for the effectiveness of mentoring relationships. 
The importance of the alignment of expectations for effective mentoring relationships was observed. As such, having a common understanding of the expectations of a mentoring relationship by both the mentor and mentee, as well as having a common understanding of the processes and outcomes of mentoring enhances the mentoring relationship. It was interesting to observe that the participants in this study had contradictory perceptions and expectations about what the outcomes of the mentoring process should be. Eller et al. (2014:817) confirms the importance of alignment of expectations in social connections such as mentoring relationships. Therefore, it is imperative to outline the expectations of mentors and owner-managers at the beginning of the relationship to ensure effective mentoring, a suggestion also made by Garr and Dewe (2013:251).

Despite the fact that the participants in this study believed that cultural differences should not influence the effectiveness of mentoring relationships, cultural sensitivity of the mentor emerged as an important issue which should be understood in order to ensure effective mentoring relationships during mentoring of black-owned small businesses. Cultural sensitivity is defined as the ability of mentors to observe, understand and accept the diverse cultural values of ownermanagers during mentoring interactions. A study conducted by Chung, Bemak and Talleyrand (2007:28) supports the findings of this study that it is not important to have a mentor and mentee of the same cultural background. Rather the mentor should be culturally sensitive to the cultures of mentees for the relationships to work.

\section{Contribution}

This study has contributed to the body of knowledge on mentoring of small businesses by providing new insights into the mentoring experiences of black-owned small businesses in South Africa. The use of interviews to collect data adds to the field of small business mentoring as little information exists on mentoring for small businesses which academic researchers can use (Clutterbuck \& Abbott 2012:74) Thus, this is the first academic study that has attempted to obtain an in-depth understanding of the mentoring experiences of black small business owner-managers in South Africa. The contribution of this study is to refine mentoring theory in the context of small businesses in South Africa.

A successful mentoring relationship is vital to reach the desired outcomes of the mentoring programme (McKevitt \& Marshall 2015:265), in this case, the development of management skills for owner-managers. Thus, this study provides insight into relational conditions that should prevail to ensure effective mentoring relationships between mentors and mentees. Recommendations have been presented to these stakeholders on how they should relate to achieve the results for which mentoring was provided. Ultimately, effective mentoring relationships should equip owner-managers with management skills necessary to make proper business decisions and manage their businesses more effectively, which is essential for the survival of their businesses.

\section{Limitations and future research}

The findings in this study are based on the mentoring perceptions and experiences of participants from only two provinces in South Africa. Future research on this topic should be extended to other provinces of South Africa to identify similarities and differences in mentoring experiences of black-owned small businesses. The nature of the sample, consisting of black-owned small businesses, limits the capacity to generalise research findings across all small businesses in South Africa. Future research should be undertaken to establish whether the findings reported in this study vary significantly when a study is conducted amongst other ethnic groups. In addition, the relational conditions identified as important during mentoring of black-owned small businesses in this study could be tested empirically in future using a quantitative research design and methodology and a relatively larger sample of blackowned small businesses.

Even though culture did not feature as a separate relational condition in this study, the findings of this study reveal that culture is an important aspect in a mentoring relationship because cultural differences could have an impact on the effectiveness of these relationships. As such, future studies could explore the impact of culture in understanding the relational conditions necessary for effective mentoring relationships.

Despite these limitations, the findings of this study contribute to the body of knowledge on small business by examining the under-researched field of small business mentoring in South Africa. For this reason, many opportunities exist for future research on mentoring of small businesses.

\section{Acknowledgements Competing interests}

The authors declare that they have no financial or personal relationship(s) that may have inappropriately influenced them in writing this article.

\section{Authors' contributions}

M.J.M. (Nelson Mandela Metropolitan University) was the project leader, together with E.V. (Nelson Mandela Metropolitan University) as well as C.R. (Nelson Mandela Metropolitan University) who supervised this study from the design until execution.

\section{References}

Adams, B.G., Van de Vijver, F. \& De Bruin, G.P., 2012, 'Identity in South Africa: Examining self-descriptions across ethnic groups', International Journal of Intercultural Relations 36, 377-388.

Allen, T.D., Eby, L.T., O'Brien, K.E. \& Lentz, E., 2008, 'The state of mentoring research: A qualitative review of current research methods and future research implications', Journal of Vocational Behavior 73, 343-357.

Ayinde, A.T., 2011, 'Mentoring: Does it work?', IFE PsychologIA: An International Journal: Mentoring: A key Issue in Human Resource Management , 1-15.

Botha, M. \& Esterhuyze, E., 2012, 'The perceived capabilities and willingness of South African small business owners to act as business mentors', African Journal of Business Management 6(51), 12101-12113. 
Chiloane-Tsoka, E. \& Mmako, N., 2014, 'Effects of migration and immigration on SMMEs: The case study of Diepsloot informal settlement, South Africa', Problems SMMEs: The case study of Diepsloot informal settlem
and Perspectives in Management 12(4), 377-383.

Chung, R.C., Bemak, F. \& Talleyrand, R.M., 2007, 'Mentoring within the field of counselling: A preliminary study of multicultural perspectives', International Journal of Advancement of Counselling 29(1), 21-32.

Cline, M., 2011, 'Paying it forward: The relationship between mentoring and perceived ESE of Jewish South African', Unpublished Master's dissertation, University of the Witwatersrand, Johannesburg.

Clutterbuck, D. \& Abbott, P., 2012, 'Mentoring as an empowerment tool', Management Today 30(1), 74-77.

Conn, V.S., 2013, 'Mentorship moves science forward', Western Journal of Nursing Research 35(5), 543-545.

Cunningham, J. \& Hillier, E., 2013, 'Informal learning in the workplace: Key activities and processes', Education + Training 55(1), 37-51.

De Janasz, S.C. \& Godshalk, V.M., 2013, 'The role of e-mentoring in protégés' learning and satisfaction', Group Organization Management 38(6), 743-774.

De Vos, A.S., Strydom, H., Fourché, C.B. \& Delport, C.S.L., 2002, Research at grass roots: For the social sciences and human service professions, Van Schaik Publishers, Cape Town.

Distelberg, B. \& Schwarz, T.V., 2015, 'Mentoring across family-owned businesses', Family Business Review 28(3), 193-210.

DTI report, 2008, 'Annual review of small business in South Africa 2005-2007', viewed 12 August 2014, from http://www.dti.gov.za/sme_development/docs/smme report.pdf

Eller, L.S., Lev, E.L. \& Feurer, A., 2014, 'Key components of an effective mentoring relationship: A qualitative study', Nurse Education Today 34(5), 815-820.

Elo, S., Kääriäinen, M., Kanste, O., Pölkki, T., Utriainen, K. \& Kynäs, H., 2014 'Qualitative content analysis: A focus on trustworthiness, SAGE open', viewe 15 November 2014, from http://classic.sgo.sagepub.com/content/4/1 15 November 2014,

Ensher, E.A. \& Murphy, S.E., 2011, 'The mentoring relationship challenges scale: The impact of mentoring stage, type and gender', Journal of Vocational Behavior $79(1), 253-266$.

Eriksson, P. \& Kovalainen, A., 2008, Qualitative methods in business research, SAGE Publications, New Delhi.

Fajana, S. \& Gbajumo-Sheriff, M., 2011, 'Mentoring: A human resource tool for achieving entrepreneurial effectiveness', IFE PSychologIA: An Internationa Journal: Mentoring: A key Issue in Human Resource Management 420, 432.

Fatoki, O.O., 2011, 'The impact of human, social and financial capital on the performance of small and medium- sized enterprises (SMEs) in South Africa', Journal of Social Sciences 29(3), 193-204.

Finkelstein, L.M., Allen, T.D, Ritchie, T.D., Lynch, J.E. \& Montei, M.S., 2012, 'A dyadic examination of the role of relationship characteristics and age on relationship satisfaction in formal mentoring programme', European Journal of Work and Organizational Psychology 21(6), 803-827.

Fleig-Palmer, M.M. \& Schoorman, F.D., 2011, 'Trust as a moderator of the relationship between mentoring and knowledge transfer', Journal of Leadership or Organizational Studies 18(3), 334-343.

Fletcher, S.J. \& Mullen, C.A., 2012, SAGE Handbook of mentoring and coaching in education, SAGE Publications, New Delhi.

Freedman, S., 2009, 'Effective mentoring', IFLA Journal 35(2), 171-182.

Garr, R.O. \& Dewe, P., 2013, 'A qualitative study of mentoring and career progression among junior medical doctors', International Journal of Medical Education 4 247-252.

Gaunt, H., Creech, A., Long, M. \& Hallam, S., 2012, 'Supporting conservatoire students towards professional integration: One-to-one tuition and the potential of mentoring', Music Education Research 14(1), 25-43.

Ghosh, R., 2012, 'Mentors providing challenge and support: Integrating concepts from teacher mentoring in education and organisational mentoring in business', Human Resource Development Review 12(2), 144-176.

Goosen, X. \& Van Vuuren, L.J., 2005, 'Institutionalising ethics in enterprises: The role of mentoring', South African Journal of Human Resource Management 3(3), 61-71.

Haggard, D.L., Dougherty, T.W., Turban, D.B. \& Wilbanks, J.E., 2011, 'Who is a mentor? A review of evolving definitions and implications for research', Journal of Management 37(1), 280-304.

Hattingh, M., Coetzee, M. \& Schreuder, D., 2005, 'Implementing and sustaining mentoring programmes: A review of the application of best practices in the South African entrepreneurial context', South African Journal of Human Resource Management 3(3), 40-48.

Herholdt, J., (ed.), 2012, Mentoring \& coaching: Articles from the Human Capita Review, Knowres Publishing, Randburg.

Jakkie, C., 2014, 'South African futures 2030 - How Bafana Bafana made Mandela Magic', Institute for Security Studies Papers (25), 36.

Janssen, S., Van Vuuren, M. \& De Jong, M.T.D., 2015, 'Informal mentoring at work: A review and suggestions for future research', International Journal of Management Reviews. DOI: 10.111/ijmr.12069.
Kathleen, M.D., 2014, The impact of mutuality in doctoral students and faculty mentoring relationships, Unpublished Doctoral thesis, Fielding Graduate mentoring relationship
University, California.

Kochan, F., Searby, L., George, M.P. \& Edge, J.M., 2015, 'Cultural influences in mentoring endeavors: Applying the cultural framework analysis process', International Journal of Mentoring and Coaching in Education 4(2), 86-106.

Kram, K.E., 1983, 'Phases of the mentor relationship', Academy of Management Journal 26(4), 608-625.

Kram, K.E., 1985, 'Mentoring at work: Developmental relationships in organizationa life', in D.L. Haggard, T.W. Dougherty, D.B. Turban, \& J.E. Wilbanks, 2011. 'Who is a mentor? A review of evolving definitions and implications for research', Journal of Management 37(1), 280-304.

Lamb, S., 1999, 'The Holmes scholars network: A networking mentoring program of the Holmes partnership', Peabody Journal of Education 74(2), 150-162.

Leck, J. \& Orser, B., 2013, 'Fostering trust in mentoring relationships: An exploratory study', Equality, Diversity and Inclusion: An International Journal 32(4), 410-425.

Little, K., Kearney, L. \& Britner, P.A., 2010, 'Students' self-concept and perceptions of mentoring relationships in a summer mentorship program for talented adolescents', Roeper Review 32(3), 189-199.

Lucassen, A., Ehlers, K., Grobler, P.J. \& Shezi, A.L., 2013, 'Allele frequency data of 15 qutosomal STR loci in four major population groups of South Africa', International Journal of Legal Medicine. DOI 10.1007/s00414-013-0898-4.

Mann, S. \& Tang, E.H.H., 2012, 'The role of mentoring in supporting novice English language teachers in Hong Kong', TESOL Quarterly 46(3), 472-494.

McGill, C.J.D., 2011, 'Creating opportunities with mentoring relationships', viewed 08 September 2014, from http://www.lamergray.com/gray/research/AlJ2011confproceed.pdf\#page $=104$

McKevitt, D. \& Marshall, D., 2015, 'The legitimacy of entrepreneurial mentoring', International Journal of Entrepreneurial Behavior \& Research 21(2), 263-280.

Moyes, D., Whittam, G. \& Ferri, P., 2012, 'A conceptualisation of the relationship capital of rural small service firms', Local Economy 27(2), 136-151.

Myers, M.D., 2013, Qualitative research in business and management, 2nd edn., SAGE Publications, New Delhi.

Ndedi, A.A., 2013, 'The incorporation of entrepreneurship in black economic empowerment programmes in South Africa', Journal of Business Management and Economics 4(9), 195-199.

NEF Annual Report, 2014, 'Foreword by the Hon. Minister of Trade and Industry', viewed 27 August 2014, from http://www.thedti.gov.za/parliament/NEF_2.pdf

Nkosi, E., Bounds, M. \& Goldman, G., 2013, 'Skills required for the management of black-owned small enterprises in Soweto', Acta Commercii 13(1), 1-10.

O'Donoghue, A. \& Shackleton, C.M., 2013, 'Current and potential carbon stocks of trees in urban parking lots in towns of the Eastern Cape, South Africa', Urban Forestry \& Urban Greening 12, 443-449.

Preisendörfer, P. \& Bitz, A., 2012, 'In search of black entrepreneurship: Why is there a lack of entrepreneurial activity among the black population in South Africa?', Journal of Developmental Entrepreneurship 17(1), 125006

Remenyi, D., 2007, Proceedings of the 6th European Conference on research methodology for business and management studies, Academic Conferences Limited, Ireland.

Rogerson, C.M., 2013, 'Improving market access opportunities for urban small, medium and micro-enterprises in South Africa', Urbani Izziv 24(2), 133-143.

Shi, L., 2008, Health services research methods, 2nd edn., Thomson, New York.

Small Business Connect, 2014, 'Small biz gets minister', Small business connect, viewed 17 June 2014, from http://www.SmallBusinessConnect.co.za

Solansky, S.T., 2010, 'The evaluation of two key leadership development program components: Leadership skills assessment and leadership mentoring', The Leadership Quarterly 21, 675-681.

Stam, A.J., 2008, The church in relation to the world, Eburon, Delft.

St-Jean, E., 2012, 'Mentoring as professional development for novice entrepreneurs: Maximising the learning', International Journal of Training \& Development 16(3), 200-216.

Swanepoel, E., Strydom, J.W. \& Nieuwenhuizen, C., 2010, 'An empirical analysis of a private company's corporate social investment in SMME development in South Africa', Southern African Business Review 14(1), 58-78.

Terblanché, S.E., 2011, 'Mentorship a key success factor in sustainable land reform projects in South Africa', South African Journal of Agricultural Extensions 39, 55-74.

Warnich, L., Drögemöller, B.I., Pepper, M.S., Dandara, C. \& Wright, G.E.B., 2011, 'Pharmacogenomic research in South Africa: Lessons learned and future opportunities in the rainbow nation', Current Pharmacogenomics and Personalized Medicine 9(3), 191-207.

Watson, G.E.H., 2004, 'A situational analysis of entrepreneurship mentors in South Africa', Masters dissertation, University of South Africa, Pretoria.

Young, K. \& Atkinson, M. (ed.), 2012, Qualitative research and physical culture, Emerald Group Publishing Limited, Bingley.

Zikmund, W.G., Babin, B.J., Carr, J.C. \& Griffin, M., 2013, Business research methods, 9th edn., Cengage Learning, Mason. 